\title{
ANALISIS PRODUKSI DAN EFISIENSI ALOKATIF USAHA BUDIDAYA IKAN NILA MERAH (Oroechromis $S p$ ) DI DESA D TEGALREJO KECAMATAN TUGUMULYO KABUPATEN MUSI RAWAS PROVINSI SUMATERA SELATAN
}

\section{PRODUCTION AND ALLOCATIVE EFFICIENCY ANALYSIS OF RED TILAPIA (Oroechromis $S p$ ) CULTIVATION IN TEGALREJO VILLAGE TUGUMULYO SUBDISTRICT MUSI RAWAS DISTRICT SOUTH SUMATERA PROVINCE}

\author{
Rommy Algamar Asri dan Nyayu Neti Arianti \\ Jurusan Sosial Ekonomi Pertanian Fakultas Pertanian UNIB
}

\begin{abstract}
This study aimed to know: 1) inputs that affect the red tilapia production (output), 2) the allocative efficiency level of the inputs, and 3) the optimum amount of the inputs that must be allocated efficiently. 35 respondents were taken by cencus method. The Cobb Douglass model was used to analyze which factors or inputs such as pond wide, red tilapia fingerlings, feed, manure and labour affect the red tilapia production. The results showed that the pond wide and feed positively affected the red tilapia production, whereasred tilapia fingerlings, manure and labour did not. The inputs allocative efficiency level of pond wide and feed were 1,900 and 1,250 or more than 1. That was meaned those inputs allocation were not efficient yet. Pond wide must to be added to the optimal level 0,96 Ha from 0,49 Ha and feed must to be added from $5.036,000$ to $6312,050 \mathrm{~kg} /$ production period.
\end{abstract}

Keywords: production analysis, input allocative efficiency, red tilapia

\section{PENDAHULUAN}

Ikan nila merah semakin marak dibudidayakan. Tingginya minat petani membudidayakan ikan nila merah dikarenakan harga jual ikan ini terus menguat, yaitu mencapai Rp16.000 hingga Rp17.000 per kg. Sementara harga nila hitam hanya Rp13.000 hingga Rp14.000 per kg. Harga ikan nila merah juga mulai menyaingi harga ikan mas. Keunggulan nila merah, selain lebih besar dari nila biasa, daging yang dihasilkan lebih tebal. Jumlah ikan nila merah dalam satu kilogram adalah 2 - 3 ekor (Anonim, 2010).

Menurut Asri (2012) budidaya ikan nila merah di Desa D Tegalrejo Kecamatan Tugumulyo Kabupaten Musi Rawas Provinsi Sumatera Selatan lebih menguntungkan dibanding ikan nila biasa. Usaha budidaya ikan nila merah memberikan ratio antara penerimaan (Revenue, R) dengan biaya produksi (Cost, C) sebesar 1,32 dengan pendapatan usaha sebesar 
Rp26.669.821/Ha/musim tebar. Sedangkan usaha budidaya ikan nila biasa hanya memiliki RC ratio sebesar 1,25 dengan pendapatan usaha sebesar Rp 20.250.161/Ha/musim tebar. Lamanya satu musim tebar adalah empat bulan.

Usaha budidaya ikan nila merah di Desa Tegalrejo Kecamatan Tugumulyo sudah efisien yang ditunjukkan nilai RC rasio-nya yang lebih besar dari satu. Namun usaha budidaya ikan nila merah seperti usaha budidaya komoditi pertanian lainnya tentu saja membutuhkan input atau faktor-faktor produksi dalam rangka mewujudkan jumlah produksi yang diharapkan. Faktor produksi dalam usaha budidaya ikan nila merah meliputi luas kolam, bibit, pakan, pupuk kandang dan tenaga kerja. Pengaruh faktor-faktor produksi tersebut dapat diketahui melalui analisis fungsi produksi.

Penggunaan input produksi seharusnya juga dipertimbangkan oleh petani ikan nila merah dalam mengalokasikan input produksi tersebut secara proporsional dengan mempertimbangkan faktor harga dari masing-masing input produksi yang digunakan. Jadi selain efisiensi usaha, perlu pula diketahui efisiensi alokasi atau penggunaan input-input produksi, yang menurut Rifiana dkk (2010) konsep tersebut dikenal dengan Efisiensi Alokatif.

Berdasarkan latar belakang tersebut, maka tujuan dari penelitian ini adalah untuk mengetahui:(a) Faktor-faktor yang mempengaruhi produksi ikan nila merah di lokasi penelitian, (b) Tingkat efisiensi alokatif penggunaan faktorfaktor produksi, dan (c) Jumlah optimal penggunaan faktor-faktor produksi tersebut sehingga kegiatan produksi berjalan efisien.

\section{METODOLOGI PENELITIAN}

Data yang digunakan dalam penelitian ini adalah data primer dan data sekunder. Data primer meliputi data survei yang dilakukan oleh Asri (2012) di Desa D Tegalrejo Kecamatan Tugumulyo Kabupaten Musi Rawas Provinsi Sumatera Selatan. Survei dilakukan terhadap 35 orang petani atau responden pemelihara ikan nila merah yang diambil secara sensus. Data-data survei tersebut terdiri dari data jumlah produksi, luas kolam, jumlah bibit yang digunakan, jumlah pakan yang diberikan, jumlah pupuk kandang dan tenaga kerja serta harga-harga masing-masing faktor produksi tersebut. Data sekunder berupa data-data dan informasi yang terkait dengan topik penelitian ini.

Menurut Pindyck, et al (1991) dan Nachrowi, dkk (2008) fungsi produksi Cobb-Douglas biasa digunakan untuk mengetahui pengaruh input terhadap output dalam suatu kegiatan produksi. Dengan demikian pengaruh masingmasing faktor-faktor produksi dalam usaha budidaya ikan nila dapat diketahui melalui fungsi produksi Cobb-Douglas yang diubah bentuknya menjadi persamaan $\ln$ atau double log agar dapat diestimasi dengan metode Ordinary 
Least Square (OLS) (Masyhuri, 2012). Dalam penelitian ini produksi ikan nila merah $(\mathrm{Y})$ merupakan fungsi dari luas kolam $\left(\mathrm{X}_{1}\right)$, jumlah bibit $\left(\mathrm{X}_{2}\right)$, jumlah pakan $\left(X_{3}\right)$, jumlah pupuk kandang $\left(X_{4}\right)$ dan jumlah tenaga kerja $\left(X_{5}\right)$.

Menurut Rifiana dkk (2010) dan Magdani dkk (2010) untuk mengetahui tingkat efisiensi alokatif penggunaan faktor produksi digunakan analisis rasio antara Nilai Produk Marjinal (NPM) dengan harga faktor produksi tersebut. Rumus yang digunakan adalah :

$$
\frac{N P M X i}{P X i}=1 \text { atau } \frac{b i \frac{Y}{X i} P y}{P X i}=1 \text { atau } X i=\frac{b i . Y . P y}{P X i}
$$

dimana NPM $x_{i}$ adalah Nilai Produksi Marjinal Faktor Produksi ke-i , $b_{i}$ adalah Elastisitas produksi (koefisien regresi) $X_{i}, Y$ adalah Rata-rata jumlah produksi $Y, X_{i}$ adalah Rata-rata penggunaan faktor produksi $X_{i}, P_{i}$ adalah Harga faktor produksi $\mathrm{X}_{\mathrm{i}}$ Py adalah Harga hasil produksi $\mathrm{Y}$.

Soekartawi (1990) dalam Warsana (2007) membagi kriteria efisiensi alokatif sebagai berikut :

$\frac{N P M X i}{P X i}=1$ berarti alokasi faktor produksi sudah efisien

$\frac{N P M X i}{P X i}>1$ berarti penggunaan faktor produksi belum efisien sehingga perlu ditambah lagi

$\frac{N P M X i}{P X i}<1$ berarti penggunaan faktor produksi tidak efisien sehingga harus dikurangi

\section{HASIL DAN PEMBAHASAN}

\section{Hasil Pendugaan Fungsi Produksi Ikan Nila Merah}

Hasil Uji Regresi fungsi produksi ikan nila merah di Desa D Tegalrejo Kecamatan Tugumulyo Kabupaten Musi Rawas Provinsi Sumatera Selatan dapat dilihat pada Tabel 1 .

Berdasarkan hasil estimasi fungsi produksi ikan nila merah dapat dijelaskan pengaruh masing-masing variabel bebas terhadap variabel terikat sebagai berikut:

\section{Luas Kolam $\left(\mathbf{X}_{1}\right)$}

Rata-rata luas kolam ikan nila merah di lokasi penelitian adalah 0,49 Ha berupa kolam air tenang. Nilai koefisien regresi untuk luas kolam adalah 0,212 dan hasil uji $\mathrm{t}$ pada taraf kepercayaan 95\% menunjukkan 
bahwa nilai $t_{\text {hitung }} 2,643$ lebih besar dari nilai $t_{\text {tabel }}$ 2,045 sehingga luas kolam berpengaruh positif terhadap produksi ikan nila merah. Nilai koefiisien regresi memberikan arti jika luas kolam mengalami peningkatan sebesar $1 \%$ maka jumlah produksi ikan nila merah akan meningkat sebesar $0,212 \%$ dan sebaliknya dengan asumsi faktor produksi lain tidak berubah. Jika kolam pemeliharaan ikan nila merah diperluas, maka areal bagi ikan untuk tumbuh semakin baik akibat persaingan antar ikan akibat kepadatan tebar yang berkurang. Dampaknya adalah ikan dapat tumbuh sempurna dan mempunyai bobot tubuh yang lebih berat sehingga produksi pun lebih tinggi. Hasil penelitian Az-zarnuji (2011) menunjukkan bahwa luas kolam berpengaruh terhadap produksi ikan lele.

Tabel 1. Hasil Estimasi dan Uji Regresi Faktor Produksi Ikan Nila Merah di Desa D Tegalrejo

\begin{tabular}{|c|c|c|c|}
\hline Variabel & $\begin{array}{c}\text { Koefisien } \\
\text { Regresi }\end{array}$ & $\begin{array}{c}\text { Kesalahan } \\
\text { Baku }\end{array}$ & $\mathbf{t}_{\text {hitung }}$ \\
\hline Konstanta & 2,138 & 0,691 & 3,096 \\
\hline $\log X_{1}($ Luas Kolam $)$ & 0,212 & 0,080 & $2,643^{*}$ \\
\hline $\log X_{2}$ (Jumlah Bibit) & $-0,013$ & 0,043 & $-0,297$ \\
\hline Log $X_{3}$ (Jumlah Pakan) & 0,732 & 0,072 & $10,200^{*}$ \\
\hline Log $\mathrm{X}_{4}$ (Jumlah Pupuk Kandang) & 0,046 & 0,038 & 1,219 \\
\hline Log X5(Jumlah Tenaga Kerja) & $-0,022$ & 0,014 & $-1,581$ \\
\hline $\begin{array}{ll}\mathrm{R}^{2} & =0,984 \\
\mathrm{t}_{\text {tabel }}(0,025 ; 29) & =2,045\end{array}$ & & & \\
\hline
\end{tabular}

Sumber: Data diolah, 2012.

Keterangan : * nyata pada taraf kepercayaan 95\%

\section{Jumlah Bibit $\left(X_{2}\right)$}

Jumlah rata-rata bibit yang digunakan di lokasi penelitian adalah sebanyak 41.114 ekor/UT atau 83.155 ekor/Ha. Koefisien regresi untuk variabel jumlah bibit adalah-0,013 dan hasil uji t menunjukkan bahwajumlah bibit tidak berpengaruh terhadap produksi ikan nila merah. Hal ini kemungkinan disebabkan oleh terlalu rendahnya jumlah bibit yang ditebar yakni rata-rata hanya $8 \mathrm{ekor} / \mathrm{m}^{2}$. Menurut hasil penelitian Sunarno (1981) kepadatan tebar ikan nila yang ideal adalah 10 ekor $/ \mathrm{m}^{2}$. Tingkat kepadatan tersebut merupakan kondisi terbaik untuk memperoleh laju pertumbuhan mutlak yang tertinggi dari ikan nila. Selanjutnya menurut Shafrudin dan Setiawati (2006) jika kepadatan tebar terlalu rendah, maka pertumbuhan ikan tidak terlalu pesat, sehingga produksi akhir tidak maksimal. 


\section{Jumlah Pakan $\left(X_{3}\right)$}

Pakan yang diberikan dalam budidaya ikan nila merah di daerah penelitian berupapelet. Rata-rata jumlah pakan yang diberikan dalam satu musim tebar adalah sebanyak $5.036 \mathrm{~kg} / \mathrm{UT}$ atau sebanyak $10.183 \mathrm{~kg} / \mathrm{Ha}$.

Nilai koefisien variabel jumlah pakan sebesar 0,732 dan berpengaruh positif terhadap produksi ikan nila merah di daerah penelitian. Hasil uji pada taraf kepercayaan 95\% menunjukkan nilai $t_{\text {hitung }}$ lebih besar dari nilai $\mathrm{t}_{\text {tabel. }}$ Jika jumlah pakan ditingkatkan $1 \%$ maka jumlah produksi ikan nila merah akan meningkat sebesar $0,732 \%$ atau sebaliknya dengan asumsi variabel lain tetap.

Pertumbuhan dan perkembangan ikan ditentukan oleh jumlah pakan yang diberikan, terutama ikan yang dipelihara dalam kolam. Pemberian pakan yang disesuaikan dengan periode pertumbuhan dan perkembangan ikan akan memberikan hasil yang baik. Hasil penelitian Merauke (2012) tentang faktor penentu produksi ikan lele dumbodiperoleh hasil bahwa jumlah pakan yang diberikan berpengaruh positif terhadap produksi. Siregar (2000) juga menyatakan penambahan jumlah pakan meningkatkan jumlah produksi ikan nila dalam keramba apung dan sebaliknya.

\section{Jumlah Pupuk Kandang $\left(X_{4}\right)$}

Hasil analisis data menunjukkan bahwa nilai koefisien regresi untuk variabel pupuk kandang adalah 0,046 . Nilai thitung yang lebih kecil daripada nilai $t_{\text {tabel }}$ memberikan arti bahwa jumlah pupuk kandang yang diberikan dalam budidaya ikan nila merah tidak mempengaruhi jumlah produksi. Pupuk kandang berfungsi untuk menumbuhkan pakan alami yang dapat dikonsumsi ikan nila merah yang dibudidayakan. Namun planktonplankton dan jasad renik yang tumbuh dan berkembang bukanlah menjadi makanan utama yang memacu pertumbuhan ikan nila merah. Pakan tambahan berupa pelet diberikan dalam jumlah yang lebih besar sehingga lebih berperan dalam proses tumbuh kembang ikan nila merah. Az-zarnuji (2011) menyatakan berdasarkan hasil penelitian yang telah dilakukannya tentang produksi ikan lele, jumlah pupuk yang diberikan juga tidak berpengaruh terhadap produksi.

\section{Jumlah Tenaga Kerja $\left(X_{5}\right)$}

Koefisien variabel jumlah tenaga kerja bernilai -0,022. Jika dibandingkan dengan nilai $t_{\text {tabel, }}$ maka $t_{\text {hitung }}$ untuk variabel tenaga kerja lebih kecil. Hal ini menunjukkan bahwa jumlah tenaga kerja juga tidak berpengaruh terhadap jumlah produksi ikan nila merah. Hasil penelitian Siregar (2000) juga menunjukkan bahwa jumlah jam kerja tidak berpengaruh terhadap produksi ikan nila dalam keramba apung. Demikian pula hasil penelitian tentang produksi ikan lele, dimana jumlah tenaga kerja tidak berpengaruh terhadap produksi (Az-zarnuji, 2011). 
Tenaga kerja dalam usaha budidaya atau pembesaran ikan nila hanya berperan dalam persiapan kolam, pemberian pupuk kandang, penebaran benih, pemberian pakan, pemeliharaan kolam dan pemanenan. Pertumbuhan dan perkembangan ikan lebih dipacu oleh jumlah pakan yang dikonsumsinya.

\section{Efisiensi Alokatif Faktor Produksi}

Berdasarkan hasil analisis fungsi produksi Cobb-Douglas ada dua faktor yang berpengaruh terhadap produksi ikan nila merah di daerah penelitian, yaitu luas kolam $\left(X_{1}\right)$ dan jumlah pakan $\left(X_{3}\right)$. Efisiensi alokatif faktor produksi disajikan dalam Tabel 2.

Tabel 2. Hasil Analisis Alokatif Faktor Produksi Ikan Nila Merah.

\begin{tabular}{lrr}
\hline \multicolumn{1}{c}{ Variabel } & \multicolumn{1}{c}{ Luas Kolam } & Jumlah Pakan \\
\hline $\mathrm{X}_{\mathrm{i}}$ & 0,49 & $5.036,00$ \\
$\mathrm{PX}_{\mathrm{i}}$ & $12.000 .000,00$ & $6.349,00$ \\
$\mathrm{Y}$ & $3.284,00$ & $3.284,00$ \\
$\mathrm{P}_{\mathrm{Y}}$ & $16.671,00$ & $16.671,00$ \\
$\mathrm{~b}_{\mathrm{i}}$ & 0,21 & 0,73 \\
$\mathrm{NPM}_{X} / \mathrm{P}_{\mathrm{x}}$ & 1,90 & 1,25 \\
Kriteria & Belum efisien & Belum Efisien \\
\hline $\mathrm{X}_{\mathrm{i}}$ optimal & 0,96 & 6312,05 \\
\hline
\end{tabular}

Sumber: Data Diolah, 2012

Sewa kolam adalah sebesar Rp 12.000.000,00/musim tebar seperti yang digunakan oleh Anonim (2009). Kondisi kolam dengan besaran sewa tersebut sama dengan kondisi kolam di lokasi penelitian. Alokasi input atau faktor produksi luas kolam memiliki tingkat atau nilai efisiensi sebesar 1,90 atau lebih besar daripada 1 yang memberikan arti bahwa luas kolam yang digunakan masih belum efisien atau belum berada pada tingkat penggunaan yang optimal sehingga harus ditambah.

Hasil perhitungan menunjukkan bahwa luas kolam yang optimal dialokasikan dalam usaha budidaya ikan nila merah adalah 0,960 Ha. Untuk itu, supaya efisien maka petani pembudidaya ikan nila merah disarankan untuk melakukan ekstensifikasi kolam dari rata-rata 0,490 Ha menjadi 0,960 Нa atau jika akan memulai usaha baru, maka luas kolam disarankan 0,96 Ha agar usaha budidaya ikan nila di lokasi penelitian efisien. Namun perlu dipertimbangkan pula kemampuan finansial petani. Sementara nilai efisiensi alokatif input atau faktor produksi jumlah pakan adalah 1,25 atau lebih besar daripada 1 sehingga dinyatakan belum efisien. Agar penggunaan pakan menjadi efisien maka jumlah pakan yang diberikan perlu ditambahkan dari rata-rata $5.036 \mathrm{~kg}$ menjadi $6.312,05 \mathrm{~kg}$ per musim tebar. 


\section{KESIMPULAN DAN IMPLIKASI KEBIJAKAN}

Kesimpulan yang dapat dirumuskan dari hasil penelitian dan pembahasan adalah:

1. Faktor atau variabel luas kolam dan jumlah pakan berpengaruh positif terhadap produksi ikan nila merah di Desa D Tegalrejo, sementara faktor jumlah bibit, jumlah pupuk kandang dan jumlah tenaga kerja tidak berpengaruh,

2. Nilai efisiensi alokatif faktor luas kolam dan jumlah pakan masingmasing adalah 1,90 dan 1,25 atau lebih besar dari 1 yang berarti belum efisien sehingga perlu ditambah lagi penggunaannya, dan

3. Jumlah optimal alokasi faktor produksi luas kolam adalah 0,96 $\mathrm{Ha}$, sedang untuk jumlah pakan adalah $6312,05 \mathrm{~kg}$ per musim tebar.

Berdasarkan kesimpulan di atas, disarankan agar epada petani pengusaha budidaya ikan nila merah di Desa Tegalrejo dapat menambah luas kolam dan jumlah pakan sesuai dengan jumlah optimal yang diperoleh dari hasil analisis agar alokasinya menjadi efisien. Namun perlu juga mempertimbangkan kemampuan modal yang dimiliki petani serta kebutuhan ikan akan pakan.

\section{DAFTAR PUSTAKA}

Anonima. 2009. Analisa Keuntungan Usaha Pembesaran Ikan Nila. http://www.ikannila.com. Diunduh Tanggal 16 Desember 2012 Pukul 21.36 WIB.

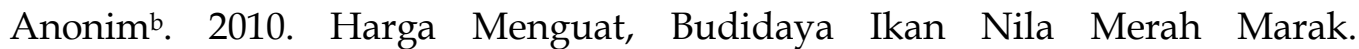
http://www.metrotvnews.com. Diunduh Tanggal 29 November 2012 Pukul 19.00 WIB.

Asri, Rommy Algamar. 2012. Analisis Pendapatan dan Efisiensi Usaha Ikan Nila Merah (Oroechromis Sp) dan Ikan Nila Biasa (Oroechromis niloticus) pada Kolam Air Tenang di Desa D Tegal Rejo Kecamatan Tugumulyo Kabupaten Musi Rawas Provinsi Sumatera Selatan. Skripsi Jurusan Sosial Ekonomi Pertanian Fakultas Pertanian Universitas Bengkulu. Bengkulu. Tidak Dipublikasikan.

Az-zarnuji, Ahmad Taufik. 2011. Analisis Efisiensi Budidaya Ikan Lele di Kabupaten Boyolali (Studi Kasus di Kecamatan Sawit Kabupaten Boyolali). Skripsi Fakultas Ekonomi Universitas Diponegoro. Semarang. http://www.docstoc.com. Diunduh Tanggal 5 Desember 2012 Pukul 17.45 WIB.

Magdani, Karina, Effy Yuswita dan Agustina Shinta. 2010. Pengaruh Faktorfaktor Produksi dan Efisiensi Alokatif Labu Butternut Organik di P.T. 
Herbal Estate Kota Baru. http://www.shinta.lecture.ub.ac.id. Diunduh Tanggal 29 November 2012 Pukul 10.09 WIB.

Masyhuri. 2012. Interpretasi Ekonomi Hasil Analisis Statistik melalui Pendekatan Elastisitas. http://www.ejournal.uin-malang.ac.id. Diunduh Tanggal 15 Desember 2012 Pukul 20.51 WIB.

Merauke, Juntak. 2012. Pengaruh Teknologi Pakan terhadap Produksi dan Keuntungan Budidaya Ikan Lele Dumbo pada Lahan Kering di Kabupaten Gunungkidul. Thesis Agribisnis Fakultas Pertanian UPN "VETERAN" Yogyakarta. http://www. repository.upnyk.ac.id. Diunduh Tanggal 5 Desember 2012 Pukul 21.20 WIB.

Nachrowi, Djalal dan Hardius Usman. 2008. Penggunaan Teknik Ekonometri: Pendekatan Populer dan Praktis Dilengkapi Teknik Analisis dan Pengolahan Data dengan Menggunakan Paket Program SPSS. Edisi Revisi. PT. Raja Grafindo Persada. Jakarta.

Pindyck, Robert, S., dan Daniel L. Rubinfeld. 1991. Econometric Models and Economic Forecasts. Third Edition. McGraw-Hill, Inc. Singapore.

Rifiana, Emy Rahmawati dan Kamiliah Wilda. 2010. Efisiensi Teknis dan Ekonomis Usahatani Padi Sawah Lahan Pasang Surut di Kabupaten Banjar Kalimantan Selatan. http://www.fapertaunlam.ac.id. Diunduh Tanggal 29 November 2012 Pukul 11.00 WIB.

Shafrudin, D., Yuniarti dan M. Setiawati. 2006. Pengaruh Kepadatan Benih Ikan Lele Dumbo (Clarias Sp.) terhadap Produksi pada Sistem Budidaya dengan Pengendalian Nitrogen melalui Penambahan Tepung Terigu. http://journal.ipb.ac.id. Diunduh Tanggal 14 Desember 2012 Pukul 19.15 WIB.

Siregar, Chrisman B.H. 2000. Analisa Faktor-faktor yang Mempengaruhi Produksi Ikan Nila di Desa Sibaganding Kecamatan Girsang Sipangan Bolon Kabupaten Simalungun. http://www.repository.usu.ac.id. Diunduh Tanggal 14 Desember 2012 Pukul 14.58 WIB.

Sunarno, Tri Joko. 1981. Pengaruh Padat Penebaran terhadap Pertumbuhan, Mortalitas, dan Produksi Ikan Nila pada Kantong Jaring Terapung di Danau Lido Cigombong Kabupaten Bogor.

http://www.repository.usu.ac.id. Diunduh Tanggal 14 Desember 2012 Pukul 19.33 WIB. 